\title{
NEW ANTIFRICTION COMPOSITE MATERIALS BASED ON TOOL STEEL GRINDING WASTE
}

\author{
KRZYSZTOF JAMROZIAK ${ }^{1} \&$ TETIANA ROIK ${ }^{2}$ \\ ${ }^{1}$ Department of Mechanics, Materials Science and Engineering, \\ Wrocław University of Science and Technology, Poland \\ ${ }^{2}$ National Technical University of Ukraine, Igor Sikorsky Kyiv Polytechnic Institute, Ukraine
}

\begin{abstract}
This paper studies the effect of technological parameters to the manufacture of new effective antifriction composite materials based on 7HG2VMF tool steel grinding waste with $\mathrm{CaF}_{2}$ additions as solid lubricants in structures, having mechanical and tribological properties for high temperature friction (bearings perform at a temperature of up to $550^{\circ} \mathrm{C}$, a sliding speed of $1 \mathrm{~m} / \mathrm{s}$, and a pressure up to 5.0 $\mathrm{MPa}$, in air). This paper illustrates the mechanism of structure formation of the new materials and its effect on properties after using developed technological modes. Such technology can ensure a microheterogeneous fine-grained structure. The composite structure consists of a matrix based on tool steel waste and the uniformly distributed $\mathrm{CaF}_{2}$ solid lubricant. The metal matrix is pearlite and consists of an $\alpha$-solid solution based on iron with hard grains of alloying elements of carbides. Such heterogeneous structure promotes a high level of antifriction properties under severe operating conditions. The behavior of $\mathrm{CaF}_{2}$ in the friction area under high temperature operating conditions has been shown. The $\mathrm{CaF}_{2}$ solid lubricant is evenly distributed over the entire friction surface. Calcium fluoride and chemical elements of the contact pair form an antifriction film, which provides self-lubricating conditions. The possibility of predicting and controlling the behavior of antifriction materials at a high temperature, by the selection of initial metal grinding waste, for ensuring the high level of functional properties, has been demonstrated. The use of grinding waste to produce effective antifriction materials makes it possible to partially solve the global problem of environmental protection.
\end{abstract}

Keywords: antifriction composite material, grinding waste, tool steel, solid lubricant, technology, structure, properties, friction films.

\section{INTRODUCTION}

Materials that operate under severe operating conditions, such as high speeds, pressures, and aggressive environments, occupy a special place among the existing antifriction ones and are studied by experimental or numerical methods [1]-[3]. Bearing materials based on iron are often used under working conditions in the air at temperatures of $500-600^{\circ} \mathrm{C}$ and high stresses (of up to $5 \mathrm{MPa}$ ), since other materials, primarily based on non-ferrous metals, show either low tribological properties or are not able to be suitably operated under such conditions. In addition, many cast materials significantly increase the cost of the friction unit and the mechanism as a whole [1], [4].

The iron-based materials do not satisfy the growing needs of modern machines for withstanding severe friction conditions, for example high temperatures. In some cases, cast materials have insufficient performance (high friction and wear coefficients) or are generally inoperable. Powder materials have a high cost due to the high price of raw materials (starting powders) [4], [5].

At the same time, large potential sources of cheap valuable raw materials exist at plants. These are grinding wastes of ferrous and non-ferrous metals and alloys of machine-building, metallurgical, tool-making industries, which are taken to the dump because of their abrasive contamination and are not used in the repeated cycle of production. Such specified 
waste contains a significant number of valuable alloying elements, such as $\mathrm{W}, \mathrm{Mo}, \mathrm{V}, \mathrm{Co}$, $\mathrm{Al}, \mathrm{Ti}, \mathrm{Cr}, \mathrm{Nb}$, etc. After proper processing, these wastes can be used in the further production cycle in particular for the production of effective slide bearings, as initiated by the authors [1], [4].

Therefore, the creation of new composite antifriction materials which are made of cheap and valuable raw materials with high operational properties under severe conditions is very relevant and requires a scientific and practical approach. This is especially important when it comes to searching for cheap raw materials and the implementation of tasks related to developing new resource-saving technologies.

The friction processes analysis shows that the wear rate of the friction surfaces is determined by the properties of the formed separating antifriction films (so called secondary structures) and depends on their nature [5]-[7]. The films on the contact surfaces can have a positive effect, minimizing the frictional forces and preventing the adhesion of the bearing and shaft, and a negative impact, when the friction film acts as abrasive depending on the working conditions. This is particularly important for friction under self-lubricating conditions. Moreover, during the friction films forming process, not only the separate property of the composite is significant, but the whole complex of properties affects the long and reliable operation of the antifriction material. These properties depend on the presence of alloying elements in the material, which are capable of forming such a structure that will ensure the effective formation of antifriction films and provide the required level of the functional properties.

The issue of using industrial metal waste in the recycling cycle is extremely important. Many scientists around the world devote their research to the problem of recycling and reuse of ferrous and nonferrous metal waste. Typically, such waste is a metal chip, scrub, etc. Such waste is the raw material for the production of new structural parts and tools which are manufactured using different technologies [8]-[10]. However, information on the reuse of grinding metal waste is somewhat limited.

Research in recent years has shown the suitability of using some steel and alloy grinding waste for the qualitative structural parts production [1], [8], [11]. The authors [8], [11] carried out experiments and received positive results on the use of some non-ferrous alloys and steel grinding waste for the manufacture of new bearing composite materials. However, studies on the use of grinding waste from a wide range of steels and alloys for composite antifriction materials were carried out in a limited number. Only individual publications have shown the prospect of this scientific direction.

The indicated arguments were the reason for comprehensive studies on the structural features, properties, and the composition of friction films of new antifriction composite materials based on the tool steel 7HG2VMF grinding waste depending on the synthesis modes. This is a significant problem both from a scientific and a practical point of view.

Solving this problem will allow the wide use of valuable grinding waste for the production of effective composite materials for various functional applications. The application of industrial grinding waste in the further production cycle will contribute to the partial solution of the environmental protection problem.

The objective of this research is to study structural features, properties, and the antifriction film composition of a self-lubricating antifriction composite material based on the tool steel 7HG2 VMF grinding waste with $\mathrm{CaF}_{2}$ solid lubricant additives for high-temperature friction units. 


\section{EXPERIMENTAL PROCEDURE}

\subsection{Preparatory procedures}

The subject of study is a new antifriction composite material based on the tool steel 7HG2VMF grinding waste with the $\mathrm{CaF}_{2}$ solid lubricant (Table 1) [12].

Table 1: Chemical composition of the materials based on the tool steel 7HG2VMF grinding waste.

\begin{tabular}{|c|c|c|c|c|c|c|c|c|c|c|}
\hline \multicolumn{10}{|c|}{ Components, wt.\% } \\
\hline $\mathrm{C}$ & $\mathrm{W}$ & $\mathrm{Cr}$ & $\mathrm{Mo}$ & $\mathrm{Si}$ & $\mathrm{Mn}$ & $\mathrm{V}$ & $\mathrm{S}$ & $\mathrm{P}$ & $\mathrm{Fe}$ & $\mathrm{CaF}_{2}$ \\
\hline $0.68-$ & $0.55-$ & $1.5-$ & $0.5-$ & $0.2-$ & $1.8-$ & $0.1-$ & $0.02-$ & $0.02-$ & \multirow{2}{*}{ basis } & $4.0-$ \\
0.76 & 0.9 & 1.8 & 0.8 & 0.4 & 2.3 & 0.25 & 0.03 & 0.03 & & 8.0 \\
\hline
\end{tabular}

The 7HG2VMF steel is the closest analogue to the AM6F2 tool steel, AISI standard, USA. The steel 7HG2VMF grinding waste is formed during the grinding process of punches and dies. The waste is polluted with abrasive particles from grinding wheels. Therefore, such waste is not usually used in the subsequent production cycle. However, this steel contains valuable alloying elements (Table 1). Hence it is attractive for use as the basis for high-temperature antifriction material. The magnetic separation method was used to clean the grinding waste from the abrasive particles through using a magnetic separator [1]. The abrasive remains constituted $1-2 \%$ after the metal waste powders had been cleaned.

After cleaning, the metal powders were subjected to regenerative annealing at temperatures of $870-1000^{\circ} \mathrm{C}$ in a hydrogen atmosphere for removing excess oxygen. The regenerative annealing reduces the total concentration of oxygen in powders from $1.0 \%$ in the initial content to $0.4 \%$ after annealing. The above contributes to the formation of a homogeneous microstructure. The remains of the casting structure are observed in samples made from non-annealed powders in the form of heterogeneous carbide grain-boundary accumulations of a biographical character. However, the carbides are spheroidized after regenerative annealing, and the material's strength increases [13], [14]. A solid lubricant powder of calcium fluoride was added to the original mixture (Table 1). $\mathrm{CaF}_{2}$ was chosen to be added to the antifriction material because it is a high-temperature and chemically stable solid lubricant. This solid lubricant is known to be effective at elevated and high temperatures and retains its properties at a temperature $t$ up to $1300^{\circ} \mathrm{C}$ [15], [16]. The $\mathrm{CaF}_{2}$ amount was chosen within the range of $4.0-8.0 \mathrm{wt} . \%$ because of the following reasons: at a quantity less than $4 \%$ of $\mathrm{CaF}_{2}$, the function of the solid lubrication is not fully realized, and when the content exceeds $10 \%$ the strength and plasticity of the material are very low. Thus, in the experiments, the authors have examined the antifriction composite materials: powders of steel $7 \mathrm{HG} 2 \mathrm{VMF}+(4.0-8.0) \% \mathrm{CaF}_{2}$.

\subsection{Preparation of powder charge and compaction}

The initial components such as the regenerated powder waste of the tool steel 7HG2VMF and the solid lubricant $\left(\mathrm{CaF}_{2}\right)$ were mixed up for 4 hours. Then the powder mixture was subjected to pressing. The pressing process was carried out under a pressure of 700-900 $\mathrm{MPa}$. 


\subsection{Sintering}

The samples were sintered in an atmosphere of shielding gas $\left(\mathrm{H}_{2}\right)$ in a laboratory furnace at $t=1100-1150^{\circ} \mathrm{C}$ for $2 \mathrm{~h}$.

\subsection{Examination techniques}

The composite structure was studied using optical and raster electron microscopes; calcium fluoride in the matrix was identified using scanning electron microscopy (SEM). The mechanical properties of the samples were determined as well. Tribological tests were performed on a VMT-1 friction testing machine (at temperature of up to $550^{\circ} \mathrm{C}$, sliding speed $V=1.0 \mathrm{~m} / \mathrm{s}$, and load $P$ of up to $5.0 \mathrm{MPa}$ ), the counterface was made of R18 cast tool steel (hardness 57-59 HRC). The counterface material R18 steel corresponded to the material of real shafts in the high-temperature friction units. The R18 steel has the following chemical composition, wt.\%: $0.73-0.83$ carbon, up to 0.5 silicon, up to 0.5 manganese, $3.8-4.4$ chromium, $17.0-18.0$ tungsten, up to 1.0 molybdenum, $1.0-1.4$ vanadium, up to 0.03 sulfur, up to 0.03 phosphorus, and iron as the base.

\section{EXPERIMENTAL RESULTS AND DISCUSSION}

A heterogeneous composite material was formed after the sintering process. The new composite structure consists of a metal matrix and inclusions of $\mathrm{CaF}_{2}$ solid lubricant (Fig. 1).

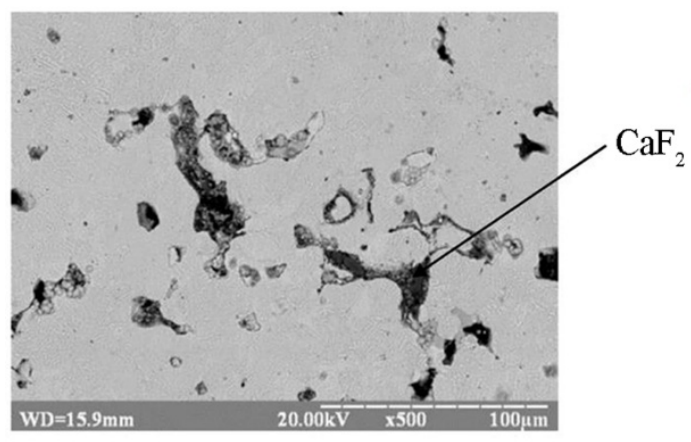

(a)

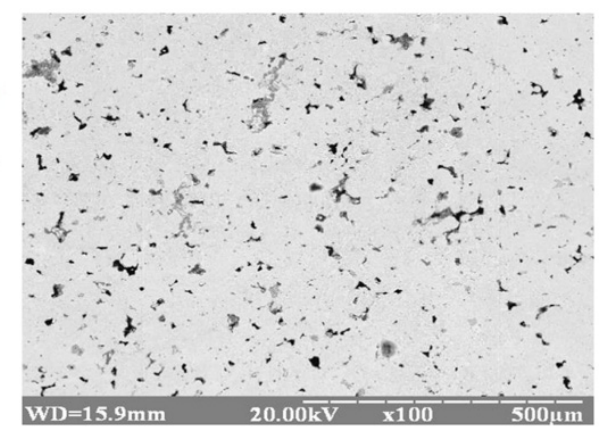

(b)

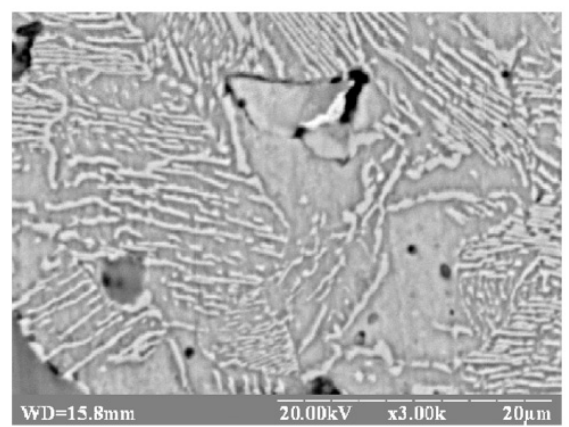

(c)

Figure 1: Images of composite microstructure, non-etched section. (a) Electron microscopic photo; (b) Optical microscopic photo; (c) Pearlitic phase fragment. 
It can be seen on Fig. 1 that the $\mathrm{CaF}_{2}$ solid lubricant is uniformly distributed over the entire composite material. The metal matrix is pearlite (Fig. 1(c)) where the carbide phases have been presented as alloying elements of carbides. These carbides are described by formulas $\mathrm{Me}_{23} \mathrm{C}_{6}, \mathrm{Me}_{2} \mathrm{C}, \mathrm{Me}_{6} \mathrm{C}$ and $\mathrm{MeC}$. Such phases are characteristic of a cast tool steel. In our case, a thin foil was prepared to identify the carbides in the new composite. Carbides presence was confirmed by electron diffraction using an electron microscope, followed by calculation of the lattice parameters (Figs 2 and 3).

The alloying elements in the waste powders contribute to the formation of the phases which are responsible for the formation of exploitation properties. It should be noted that the influence of alloying elements on the characteristics of the composite depends on the method of their introduction into the material.

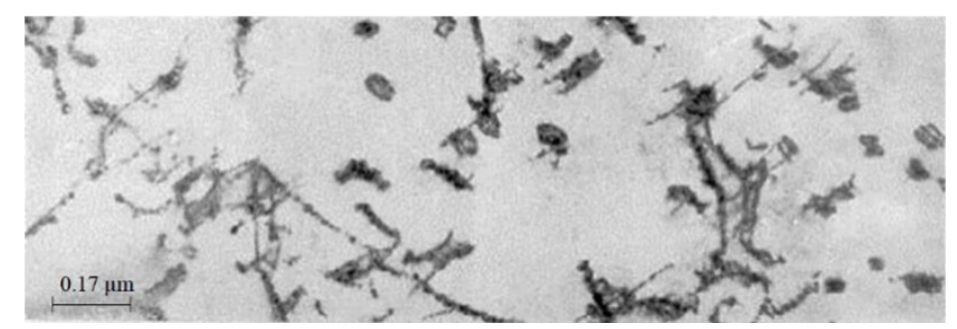

Figure 2: $\mathrm{Mo}_{2} \mathrm{C}$ carbides in metal matrix.

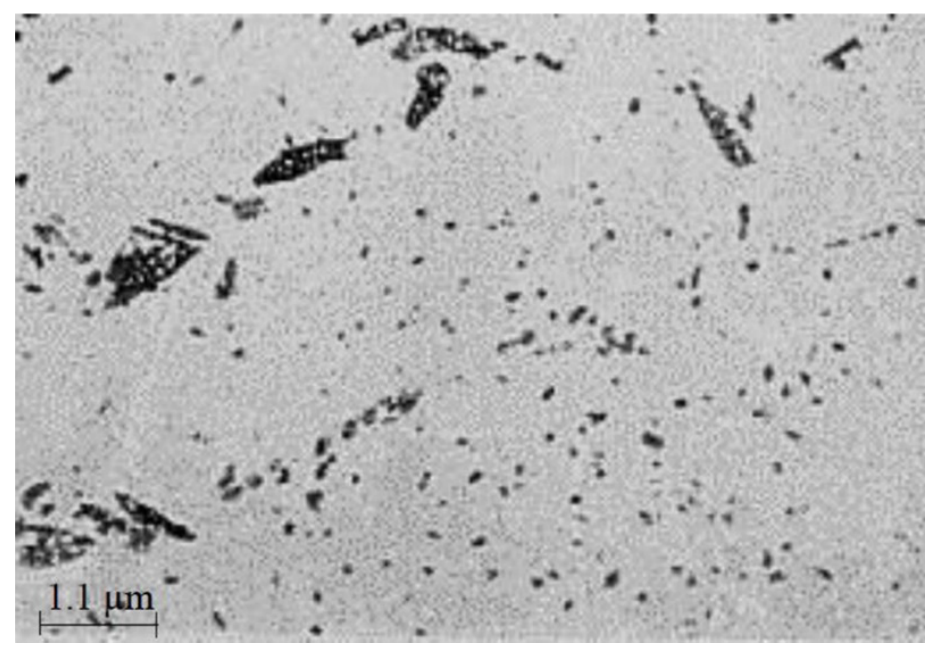

Figure 3: $(\mathrm{Fe}, \mathrm{Cr})_{23} \mathrm{C}_{6}, \mathrm{VC}$ and $(\mathrm{Fe}, \mathrm{Cr}, \mathrm{Mo})_{6} \mathrm{C}$ carbides in metal matrix.

Addition of pure $\mathrm{Cr}$ powders leads to the formation of an extremely heterogeneous structure of the matrix. That is due to the deceleration of chromium dissolution processes on the iron base because of its high oxidation and ability of forming carbides [17]. However, the production of the composite made from the alloyed primary raw material provides a more homogeneous structure with higher mechanical properties. Such a structure has provided the development of the properties presented in Table 2 . 
Tribological and mechanical properties of the examined materials have been presented in Table 2 compared to the known powder materials based on Fe [1], [5], which are used under similar conditions. Table 2 shows that the new waste-based composite material demonstrates higher antifriction properties at friction in a self-lubricating mode at high temperatures and loads than the known Fe-based composite material, which showed unsatisfactory tribological characteristics under such operating conditions.

Table 2: Properties of the examined composite.

\begin{tabular}{|c|c|c|c|c|c|}
\hline $\begin{array}{c}\text { Composition, } \\
\text { wt. } \%\end{array}$ & $\begin{array}{c}\text { Bending } \\
\text { strength, } \sigma_{\mathrm{s}}, \\
\mathrm{MPa}\end{array}$ & $\begin{array}{c}\text { Impact } \\
\text { resistance, } \\
\mathrm{KC}, \mathrm{J} / \mathrm{m}^{2}\end{array}$ & $\begin{array}{l}\text { Hardness } \\
\mathrm{HB}, \mathrm{MPa}\end{array}$ & $\begin{array}{c}\text { Friction } \\
\text { coefficient/ } \\
\text { wear rate, } \\
\mu \mathrm{m} / \mathrm{km} \\
\text { (at } 5 \mathrm{MPa} \text { and } \\
550^{\circ} \mathrm{C} \text { ) }\end{array}$ & $\begin{array}{c}\text { Maximum } \\
\text { allowable } \\
\text { load, } \mathrm{MPa} / \\
\text { temperature, } \\
{ }^{\circ} \mathrm{C}\end{array}$ \\
\hline $\begin{array}{c}\text { 7HG2VMF + } \\
4 \mathrm{CaF}_{2} \\
\end{array}$ & $590-630$ & $650-680$ & $2590-2640$ & $0.18 / 41$ & $5 / 550$ \\
\hline $\begin{array}{c}7 \mathrm{HG} 2 \mathrm{VMF}+ \\
6 \mathrm{CaF}_{2}\end{array}$ & $570-620$ & $630-670$ & $2570-2630$ & $0.16 / 39$ & $5 / 550$ \\
\hline $\begin{array}{c}\text { 7HG2VMF }+ \\
8 \mathrm{CaF}_{2}\end{array}$ & $560-600$ & $620-640$ & $2550-2620$ & $0.17 / 42$ & $5 / 550$ \\
\hline $\begin{array}{c}\mathrm{Fe}+3 \mathrm{C}+15 \mathrm{Mo} \\
(\mathrm{ZhGr} 3 \mathrm{M} 15) \\
\text { composite } \\
\text { material [1] }\end{array}$ & $240-300$ & $350-520$ & $850-950$ & $0.31 / 176$ & $1.5 / 450$ \\
\hline
\end{tabular}

The dense and continuous antifriction films were formed on the contact surfaces, both on the surface of the examined material and counterface during the tribological tests. The scanning electron microscopy confirmed the presence of a thin dense antifriction layer on the friction surfaces after tribological tests (Fig. 4).

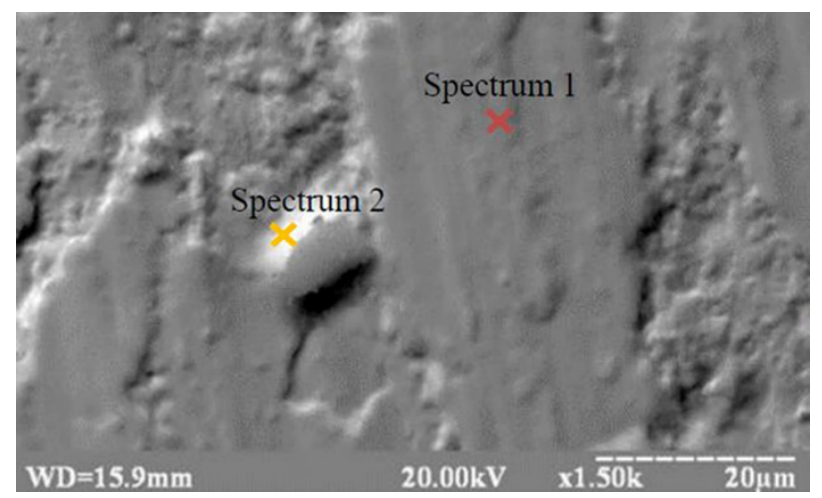

Figure 4: Friction surfaces: image in secondary electrons mode ( $\mathrm{x}-$ analysis points). 
Such films consist of contact materials alloying elements and the $\mathrm{CaF}_{2}$ solid lubricant that was confirmed by the micro X-ray spectral analysis method (Fig. 5). The chemical elements of the composite material were determined after the analysis at points (the spectra 1 and 2). The data for spectra 1 and 2 (Fig. 5) show the presence of all components from the initial charge and counterface.

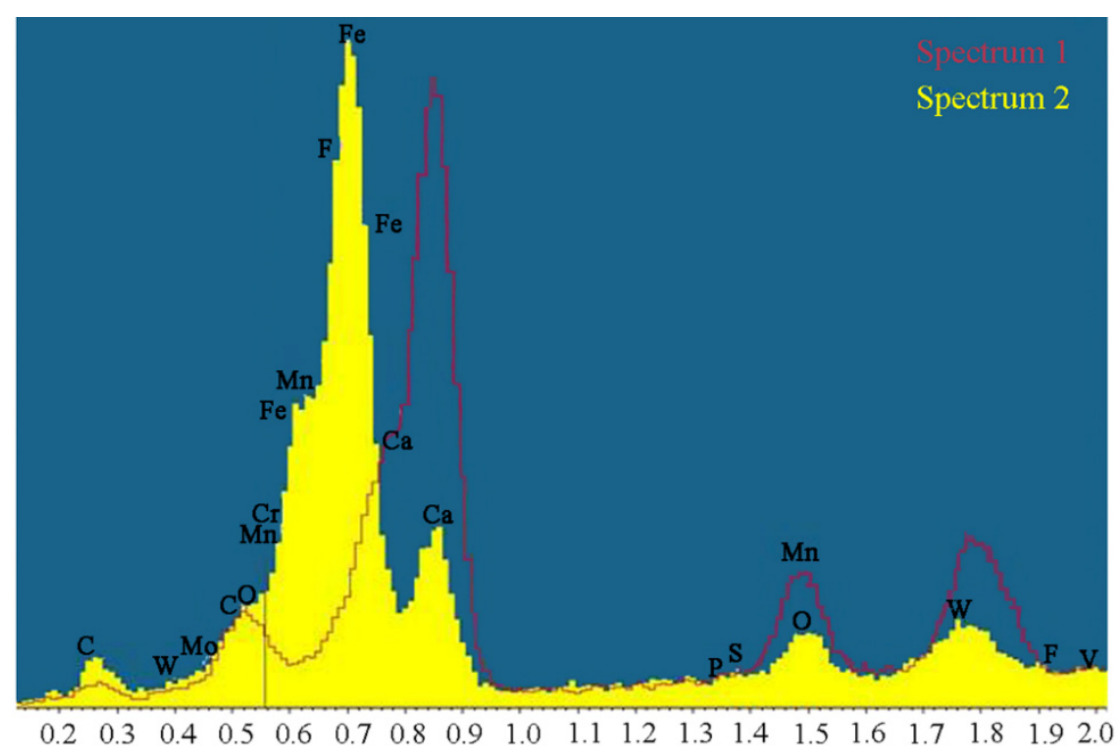

Figure 5: Spectra from selected areas of friction film.

The chemical elements ratio has been presented from the selected areas on the friction track (Fig. 5, spectra 1, 2) after tribological tests at $550^{\circ} \mathrm{C}$, load $5.0 \mathrm{MPa}$ and speed of $1.0 \mathrm{~m} / \mathrm{s}$ (Table 3).

Table 3: EDS results of the wear track in selected areas.

\begin{tabular}{|c|c|c|}
\hline Element, at.\% & Spectrum 1 & Spectrum 2 \\
\hline $\mathrm{Fe}$ & 59.00 & 68.00 \\
\hline $\mathrm{C}$ & 12.13 & 21.79 \\
\hline $\mathrm{Ca}$ & 2.53 & 5.02 \\
\hline $\mathrm{W}$ & 0.71 & 0.77 \\
\hline $\mathrm{Mo}$ & 0.80 & 0.86 \\
\hline $\mathrm{Cr}$ & 1.65 & 1.68 \\
\hline $\mathrm{Mn}$ & 2.09 & 4.22 \\
\hline $\mathrm{F}$ & 4.37 & 4.58 \\
\hline $\mathrm{O}$ & 3.14 & 11.31 \\
\hline $\mathrm{P}$ & 0.39 & 0.41 \\
\hline $\mathrm{S}$ & 0.41 & 0.43 \\
\hline $\mathrm{V}$ & 0.81 & 0.82 \\
\hline
\end{tabular}


As can be seen from the spectral microanalysis data, oxygen is also present on the contact surfaces. This suggests that oxidation processes are activated at friction in the air at elevated temperatures.

Friction films probably consist of complex oxide and fluoride formations which cover the contact surfaces and prevent the composite from volume oxidation. Under these friction conditions, there is a balance between the wear rate of these films and the rate of new areas antifriction films formation. Thus, the self-lubrication mode is realized. Friction films (secondary structures) have smooth microtopography, which minimizes wear and stabilizes the friction pair operation.

\section{CONCLUSIONS}

The studies on the example of a new antifriction composite material based on the 7HG2VMF steel grinding waste with the $\mathrm{CaF}_{2}$ solid lubricant have shown the possibility to determine the features of the formation of the material structure using grinding waste as the metal basis, taking into account the nature of the alloying elements and their phases in the metal matrix. The above allows predicting the nature of strengthening of the materials and their antifriction behavior. Such an approach opens the opportunity for controlling the composite structure and properties by the choice of initial alloyed grinding waste to form the necessary matrix basis and adding the required amount of the solid lubricant.

The analysis of tribological properties allowed determining the ranges of rational exploitation modes for the studied material: load of up to $5.0 \mathrm{MPa}$, slide speed of $1 \mathrm{~m} / \mathrm{s}$, and temperature of $500-550^{\circ} \mathrm{C}$ in the air. The developed antifriction composite can be recommended for operation in the friction units of thermal and metallurgical equipment.

Using the valuable grinding waste will allow not only manufacturing of new effective composites but also it will contribute to the partial solution of the environmental protection problem.

\section{REFERENCES}

[1] Kyrychok, P., Roik, T. \& Gavrish, A. (eds), New Composite Materials of the Printing Machines Friction Parts, Publishing House of National Technical University of Ukraine, Igor Sikorsky Kyiv Polytechnic Institute: Kiev, 2015 (in Ukrainian).

[2] Baranowski, P., Damaziak, K., Malachowski, J., Sergienko, V.P. \& Bukharov, S.N., Modeling of abrasive wear by the meshless smoothed particle hydrodynamics method. Journal of Friction and Wear, 37(1), pp. 94-99, 2016.

[3] Baranowski, P. et al., Thermovision in the validation process of numerical simulation of braking. Metrology and Measurement Systems, 21(2), pp. 329-340, 2014.

[4] Roik, T., Gavrish, A., Kirichok, P. \& Vitsyuk, Y., Effect of secondary structures on the functional properties of high-speed sintered bearings for printing machines. Powder Metallurgy and Metal Ceramics, 54(1-2), pp. 119-127, 2015.

[5] Migranov, M.S., Mukhamadeev, V.R., Migranov, A.M., Mukhamadeev, I.R. \& Khazgalieva, A.A., The improvement of the tribotechnical properties of materials and coatings for metal cutting tool. IOP Conference Series: Materials Science and Engineering, 447(012083), 2018.

[6] Roik, T.A., Kholyavko, V.V., Vitsyuk, Y.Y. \& Melnyk, O.O., Influence of mechanism of secondary-structures tribosynthesis on properties of antifriction nickel-based composite materials. Metallofizika i Noveishie Tekhnologii, 38(8), pp. 1111-1123, 2009. 
[7] Roik, T.A. \& Shevchuk, Y.F., Development of predictable secondary structures in materials for high-temperature bearings. Powder Metallurgy and Metal Ceramics, 45(11), pp. 531-539, 2006.

[8] Shpak, P.A., Hrechaniuk, V.H. \& Osokyn, V.A., Influence of electron-beam remelting on the structure and properties of high-speed steel R6M5. Problems of special metallurgy, 3, pp. 14-17, 2002.

[9] Zhang, W., Zhu, Z. \& Cheng, C.Y., A literature review of titanium metallurgical processes. Hydrometallurgy, 108(3-4), pp. 177-188, 2011.

[10] Rao, S.R., Resource Recovery and Recycling From Metallurgical Wastes, Elsevier: Oxford and Amsterdam, 2011.

[11] Roik, T., Gavrish, O., Oliynik, V. \& Vitsiuk, I., Analysis of the properties of antifriction composites based on aluminum alloy's grinding waste. Eastern-European Journal of Enterprise Technologies, 4(12), pp. 16-22, 2018.

[12] Roik, T.A., Gavrish, A.P., Gavrish, O.A., Kyrychok, P.O., Vitsiuk, I.I. \& Melnik, O.O., Antifrictional Composite Material Based on Instrumental Steel, Patent no. 102299, Bulletin no. 12, June 25, 2013 (in Ukrainian).

[13] Gheller, Y.A., Tool Steels, Metallurgy: Moscow, 1983 (in Russian).

[14] Christian, H., Tool Steel, Forskningscenter Risoe: Denmark, Risoe-R no. 1244(EN), 2001.

[15] Jamroziak, K. \& Roik, T., Structure and properties of the new antifriction composite materials for high-temperature friction units. Proceedings of the 7th International Conference on Fracture Fatigue and Wear, pp. 628-637, 2019.

[16] Jianxin, D. \& Tongkun, C., Self-lubricant mechanisms via the in situ formed tribofilm of sintered ceramics with $\mathrm{CaF}_{2}$ additions when sliding against hardened steel. International Journal of Refractory Metals and Hard Materials, 25(2), pp. 189-197, 2007.

[17] Antsiferov, V.N. \& Akimenko, V.B., Sintered alloy steels, Metallurgy: Moscow, 1983 (in Russian). 